\title{
The effects of acute citalopram dosing on gastric motor function and nutrient tolerance in healthy volunteers
}

\author{
P. Janssen, L. Van Oudenhove, C. Casteels, R. Vos, K. Verbeke \& J. Tack
}

Translational Research Center for Gastrointestinal Disorders, University of Leuven, Leuven, Belgium.

\section{Correspondence to:}

Dr P. Janssen, Translational Research Center for Gastrointestinal Disorders, University of Leuven, Herestraat 49, Bus 701, Leuven BE-3000, Belgium.

E-mail: pieter.janssen@med.kuleuven.be

\section{Publication data}

Submitted 22 September 2010

First decision 18 October 2010

Resubmitted 21 October 2010

Accepted 10 November 2010

EV Pub Online 30 November 2010

\section{SUMMARY}

\section{Background}

It is unclear whether endogenous serotonin release is involved in the regulation of gastric motility and food intake.

\section{Aim}

To study the effect of acute administration of the selective serotonin reuptake inhibitor citalopram on gastric motor function in man.

\section{Methods}

Nineteen healthy volunteers underwent a gastric barostat, gastric emptying and/or a drinking test after dosing with either placebo or citalopram (20 mg intravenously). In the barostat protocol, a flaccid bag was introduced in the stomach and inflated at intra-abdominal pressure $+2 \mathrm{mmHg}$, volume was recorded before and after administration of a liquid meal (300 kcal). Gastric emptying for solids and liquids was simultaneously assessed using the ${ }^{14} \mathrm{C}$-octanoic acid $/{ }^{13} \mathrm{C}$-glycine breath test. During the drink test, volunteers drank at a rate of $15 \mathrm{~mL} / \mathrm{min}$ until maximal satiation. Citalopram was compared with placebo using $t$-tests and mixed model analysis.

\section{Results}

Citalopram induced a significant preprandial gastric relaxation (volume increase of $154 \pm 55 \mathrm{~mL}$ vs. $-38 \pm 33 \mathrm{~mL}$ after placebo dosing; $P<0.05$ ), whereas the postprandial volume increase was significantly decreased after citalopram treatment $\left(F_{12.80}=4.78, P<0.0001\right.$; maximum volume increase was $304 \pm 40$ vs. $201 \pm 54 \mathrm{~mL}$ after placebo and citalopram treatment respectively). Citalopram enhanced solid $(123 \pm 17$ vs. $77 \pm 6 \mathrm{~min}$, $P<0.05)$ but not liquid emptying (62 \pm 6 vs. $57 \pm 4 \mathrm{~min}$ ). Satiation scores during the drink test were lower after citalopram $\left(F_{19.153}=2.02, P=0.01\right.$; volunteers drank $998 \pm 129$ vs. $765 \pm 79 \mathrm{~mL}$ after citalopram and placebo treatment respectively).

\section{Conclusion}

The observed effects indicate a role for serotonin in the control of gastric motility and food intake.

Aliment Pharmacol Ther 2011; 33: 395-402 


\section{P. Janssen et al.}

\section{INTRODUCTION}

Serotonin (5-hydroxytryptamine; 5-HT), a neurotransmitter in the enteric nervous system, is considered to play a key role in the control of gastrointestinal motility. ${ }^{1,2}$ Numerous studies have investigated the role of 5 -HT in the control of gastric motility. Several 5-HT receptor agonists were shown to affect gastric motility in health: the $5-\mathrm{HT}_{1}$ receptor agonists sumatriptan and buspirone for example enhanced accommodation to meal and slowed gastric emptying, ${ }^{3,4}$ the $5-\mathrm{HT}_{3}$ receptor agonist MKC-733 delayed liquid gastric emptying in association with relaxation of the proximal stomach ${ }^{5}$ and the $5-\mathrm{HT}_{4}$ receptor agonists tegaserod and cisapride are known to accelerate gastric emptying, and enhanced gastric accommodation. ${ }^{1}$ Although $5-\mathrm{HT}_{3}$ receptor antagonism is known to abolish spontaneous phase III contractions in the antrum, the $5-\mathrm{HT}_{3}$ receptor antagonists tropisetron and ondansetron did not significantly affect gastric tone, gastric volumes after a meal or gastric emptying. ${ }^{6-9}$ Moreover, the $5-\mathrm{HT}_{4}$ receptor antagonist R216073 did not affect fundic relaxation or drinking capacity. ${ }^{10}$ These observations question whether endogenous 5-HT release is involved in the control of gastric accommodation and emptying in man.

Selective serotonin reuptake inhibitors (SSRIs) enhance the availability of physiologically released 5-HT both centrally and peripherally, and effects of these drugs could thus indicate whether endogenously released 5-HT is involved in physiological processes. We previously showed that 7 days' pre-treatment with the SSRI paroxetine increased meal-induced gastric accommodation to a meal. ${ }^{11}$ In a similar treatment regimen, however, sertraline, paroxetine or venlafaxine-XR (selective serotonin and norepinephrine reuptake inhibitor) were shown not to affect gastric compliance, sensitivity or gastric emptying. ${ }^{12,13}$ It is difficult to understand the role of $5-\mathrm{HT}$ in gastric motility from these experiments as the observed effects, or lack of effect, could be mediated by the enhanced availability of 5-HT or desensitisation of the 5-HT receptors given the relatively long treatment period. Indeed, the presumed working mechanism of SSRI drugs in depression is desensitisation of 5-HT receptors because of the enhanced availability of physiologically released 5HT. ${ }^{14-16}$ To avoid desensitisation of 5-HT receptors and to observe the role of acutely enhanced availability of 5-HT, we aimed to study the effect of acute intravenous administration of the SSRI citalopram on gastric motor function in man.

\section{METHODS}

\section{Ethics approval}

All study procedures were approved by the ethics committee of the Leuven University Hospital, Belgium. Written, informed consent was obtained from all subjects, and studies conformed to the Declaration of Helsinki.

\section{General study design and study subjects}

This study used a randomised, placebo-controlled, single-blind, crossover design in which healthy volunteers (HVs) participated in a barostat study, a gastric emptying study and/or a nutrient challenge test. Between two visits, a washout period of at least 1 week was respected. A pool of $19 \mathrm{HVs}$ (10 men, age: $23 \pm 1$ years) with normal body mass index $(22.7 \pm 0.7 \mathrm{~kg} / \mathrm{m})$ was included in the studies. Six HVs participated in both the barostat and gastric emptying protocol, one HV participated in both the gastric emptying and drinking test protocol and four HVs participated in both the drinking test and the barostat protocol. Per-protocol volunteers always participated in both the placebo and citalopram treatment arm, hence all comparisons could be performed in a pairedwise fashion. None of the HVs had symptoms or a history of gastrointestinal disease, other significant diseases, psychological disorders or drug allergies; none were taking any medication or had any drug history.

\section{Barostat study protocol}

A double lumen polyvinyl tube (Salem sump tube 14 Ch.; Sherwood Medical, Petit Rechain, Belgium) with an adherent plastic bag (1200 mL capacity; $17 \mathrm{~cm}$ maximal diameter) finely folded, was introduced through the mouth and secured to the patient's chin with adhesive tape. The position of the bag in the gastric fundus was checked fluoroscopically.

The polyvinyl tube was then connected to a computer-driven programmable volume-displacement barostat device (Synectics Visceral Stimulator, Stockholm, Sweden). To unfold the gastric balloon initially, the HVs were asked to lie down on a bed while the balloon was inflated with a fixed-volume of $500 \mathrm{~mL}$ of air for $2 \mathrm{~min}$, then the balloon was deflated completely. After a 10-min equilibration period, the patients were positioned in a comfortable sitting position with the knees slightly bent $\left(80^{\circ}\right)$ in a bed specifically designed for that purpose.

After a 30-min equilibration period, the minimal intraballoon distending pressure (MDP) was determined as the lowest pressure level that provided an intraballoon volume of $30 \mathrm{~mL}$ or more during a protocol in which the balloon 
pressure was increased stepwise by $1 \mathrm{mmHg}$ every minute. ${ }^{11}$ The MDP represents the pressure level that equilibrates the intra-abdominal pressure. Subsequently, sequential ramp distentions were performed in stepwise increments of $2 \mathrm{mmHg}$ starting from MDP, each lasting for $2 \mathrm{~min}$, whereas the corresponding intraballoon volume was being recorded. Patients were instructed to score their perception of upper abdominal sensations induced by each distending stimulus at the end of every distending step, using a graphic rating scale that combined verbal descriptors on a scale graded from 0 to $6 .{ }^{11}$ The end point of each sequence of distentions was established at an intraballoon volume of $1000 \mathrm{~mL}$, or when the patients reported discomfort (score 5) or pain (score 6).

After another 30-min equilibration period, the intraballoon pressure level was set at $\mathrm{MDP}+2 \mathrm{mmHg}$. Thirty minutes hereafter, citalopram $(20 \mathrm{mg})$ or placebo was intravenously infused over 20 minutes using saline as vehicle. Immediately after this treatment, the volunteers were asked to consume a nutrient drink $(200 \mathrm{~mL}$; $300 \mathrm{kcal}$; $13 \%$ proteins, $48 \%$ carbohydrates, 39\% lipids; Nutridrink; Nutricia, Bornem, Belgium). Intraballoon volume measurements continued for $60 \mathrm{~min}$.

\section{Gastric emptying study protocol}

Gastric emptying for solids and liquids was simultaneously assessed using the previously validated ${ }^{14} \mathrm{C}$-octanoic acid $/{ }^{13} \mathrm{C}$-glycin breath test. ${ }^{17,}{ }^{18}$ Twenty minutes before meal intake, saline or citalopram $(20 \mathrm{mg}$ ) were administered over a 20 -min period. The test meal consisted of $60 \mathrm{~g}$ of white bread and one egg, the yolk of which was doped with $74 \mathrm{kBq}$ of ${ }^{14} \mathrm{C}$-octanoic acid sodium salt. The meal was ingested within $5 \mathrm{~min}$, followed immediately by $150 \mathrm{~mL}$ of water dosed with $100 \mathrm{mg}$ of ${ }^{13} \mathrm{C}$-glycine. The total caloric value of the test meal was $250 \mathrm{kcal}$. Breath samples were taken before the meal and at 15-min intervals for a period of $240 \mathrm{~min}$ postprandially. Gastric half emptying time $\left(T_{1 / 2}\right)$ was calculated as previously described. ${ }^{17}$

\section{Drink test protocol}

After an overnight fast, volunteers underwent a satiety drinking test to quantify nutrient tolerance and the occurrence of meal-induced satiation as previously described. ${ }^{19}$ Twenty minutes before the start of the nutrient drink ingestion, either saline or citalopram (20 mg) was administered over a 20-min period. A peristaltic pump (MINIpuls2; Gilson, Villiers-Le-Bel, France) filled one of two beakers at a rate of $15 \mathrm{~mL} / \mathrm{min}$ with a liquid meal (Nutridrink; Nutricia). Subjects were requested to maintain intake at the filling rate, thereby alternating the beakers as they were filled and emptied. At 5-min intervals, they were asked to score their satiation on a scale graded $0-5$ ( $1=$ threshold, $5=$ maximum satiety). Meal intake was stopped when a score of 5 was reached.

\section{Statistical analyses}

All analyses were done using SAS statistical software version 9.1.3 (SAS Institute, Cary, NC, USA). Data are presented as the mean \pm S.E.M. Differences were considered to be significant at the $5 \%$ level.

Barostat study. To evaluate gastric tone, the mean intraballoon volume was calculated over consecutive 5-min intervals. The first six intervals $(30 \mathrm{~min}$ ) constitute the baseline period, the following four intervals $(20 \mathrm{~min})$ the preprandial period (during which citalopram or placebo was infused) and the final 12 intervals $(60 \mathrm{~min})$ constitute the postprandial period (i.e. after nutrient drink ingestion) (Figure 1). Preprandial relaxation at each time interval of the preprandial period was quantified by subtracting the average baseline volume from the preprandial volume. Meal-induced gastric relaxation at each time interval of the postprandial period was quantified by subtracting the average preprandial volume from the postprandial volume. To compare pre- and postprandial relaxation over time between treatments, delta values $\left(\right.$ relaxation $n_{\text {placebo }}-$ relaxation $_{\text {citalopram }}$ ) were calculated at each time point; these delta values were used as the dependent variable in all analyses described below. Mixed model analysis (using 'proc mixed' in SAS) with time as a categorical fixed effect was used to test the hypothesis that this delta-relaxation curve was significantly different from zero over time, this corresponds to a treatment effect over time and will be referred to accordingly throughout this article. Random and/or repeated effects were added to the model to account for the between- and within-subject variability structure of the data in the best possible way. The model that fitted the data best (based on Akaike's Information Criterion) will be reported.

In addition, to compare volumes at certain time points, a paired Student's $t$-test was applied.

Gastric emptying. Gastric half emptying time for both solid and liquid emptying were compared using paired Student's $t$-tests.

Drink test. Satiation scores were represented as the average satiation score per $5 \mathrm{~min}$. The difference in satiation 


\section{P. Janssen et al.}

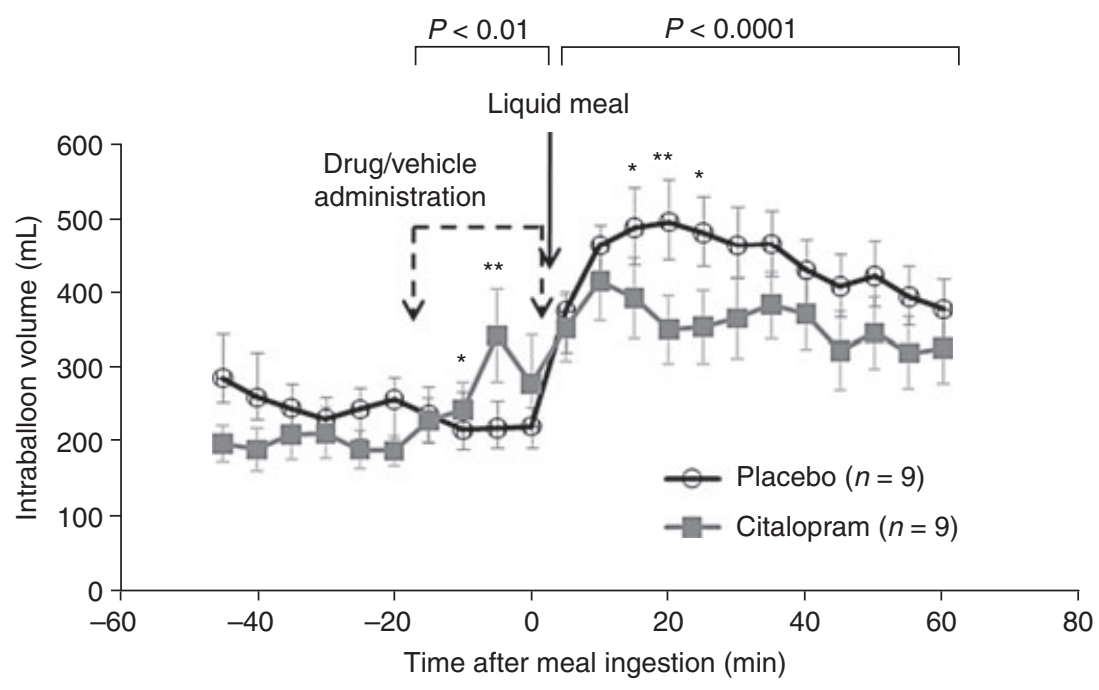

Figure 1 | Mean intraballoon volumes at 5-min intervals, before treatment, during treatment and after treatment and consumption of a liquid nutrient drink. Citalopram $(20 \mathrm{mg}$ ) or vehicle (saline) was administered as an intravenous infusion over $20 \mathrm{~min}$. During citalopram treatment a transient, significant relaxation was observed. After meal intake, the intraballoon volume increase was significantly inhibited after citalopram administration. Statistical differences at individual time points are indicated as follows: ${ }^{\star} P<0.05,{ }^{\star \star} P<0.01,{ }^{\star \star \star} P<0.001$.

score over time between both treatments was analysed using mixed model analysis as described above. Furthermore, the volume at which HVs stopped drinking was compared using Student's $t$-tests.

\section{RESULTS}

\section{Conduct of the studies}

All volunteers completed the studies as planned and no side effect was observed or reported during or after treatment with placebo or citalopram.

\section{Barostat study}

Mean baseline volumes before drug administration were not different between both treatment groups (254 \pm 31 vs. $198 \pm 26 \mathrm{~mL}$ for placebo and citalopram respectively; $n=9$; Figure 1). However, compared with placebo, administration of citalopram induced a significant preprandial relaxation (treatment effect over time $\left.F_{4,16}=5.16, P=0.007\right)$, which seemed to be transient (Figure 1): at time -5 , the volume increase was $154 \pm 55$ vs. $-38 \pm 33 \mathrm{~mL}$ after citalopram and placebo treatment respectively $(P<0.05$; paired $t$-test $)$ while at time 0 , the volume increase after citalopram treatment was reduced to $91 \pm 59$ [vs. $-36 \pm 31 \mathrm{~mL}$ after placebo treatment (N.S., paired $t$-test)]. Moreover, when comparing the mean preprandial volumes, no significant differences could be detected $(273 \pm 40$ vs. $223 \pm 28 \mathrm{~mL}$ after citalopram and placebo treatment respectively; paired $t$-test).

When comparing the mean postprandial volume after citalopram treatment $(363 \pm 41 \mathrm{~mL})$ with the mean postprandial volume after placebo treatment (439 $\pm 42 \mathrm{~mL}$ ), no significance could be detected (paired $t$-test). However, when time was taken into account, citalopram treatment significantly decreased postprandial relaxation compared with placebo (treatment effect over time $\left.F_{12,80}=4.78, P<0.0001\right)$. Significances of post hoc tests at individual time points for both analyses are shown in Figure 1.

\section{Gastric emptying}

Citalopram significantly enhanced solid $(123 \pm 17$ vs. $77 \pm 6 \min , P<0.05 ; n=10$; Figure 2$)$ but not liquid emptying (62 \pm 6 vs. $57 \pm 4 \mathrm{~min}$, N.S.).

\section{Drinking test}

Satiation scores after citalopram were consistently lower compared with placebo treatment throughout the drinking test. Although differences were relatively small, the effect of treatment over time was significant $\left(F_{19,153}=2.02, \quad P=0.01 ; n=10\right)$. Significances of post hoc tests at individual time points for both analyses are shown in Figure 3. Moreover, citalopram treatment significantly increased the amount of liquid nutrient meal 

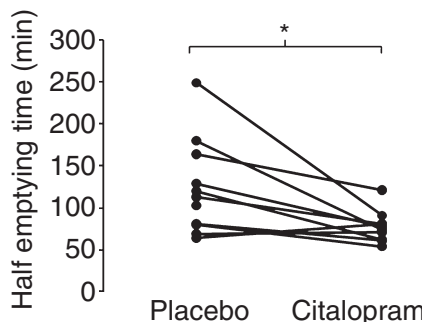

Placebo Citalopram

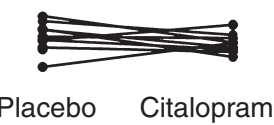

Figure 2 | Solid and liquid half-emptying rates after administration of placebo or citalopram. Citalopram significantly enhanced solid emptying $(P<0.05)$.

ingested at maximum satiation $(765 \pm 79$ vs. $998 \pm$ $129 \mathrm{~mL}, P<0.05$; Figure 3).

\section{DISCUSSION}

To date, there is an ongoing controversy regarding the role of endogenous 5-HT release in the regulation of gastric motility in man: although different 5 -HT receptor agonists have been shown to modify gastric motility, ${ }^{1,3-5}$ antagonists per se seem to lack effect. ${ }^{6-10} \mathrm{We}$ previously showed that the SSRI paroxetine enhanced gastric meal-induced accommodation. ${ }^{11}$ In the latter study, however, the observed effect could be mediated by enhanced availability of synaptically released $5-\mathrm{HT}$ or by $5-\mathrm{HT}$ receptor desensitisation due to the long treatment duration. ${ }^{16}$ In the present study, acute treatment with the SSRI citalopram transiently decreased gastric basal tone, decreased gastric accommodation, accelerated gastric emptying of solids and decreased feelings of satiation, indicating an important role for 5HT release in the regulation of stomach motility and food intake.

Citalopram is considered a highly selectively 5 -HT reuptake inhibitor. ${ }^{20}$ However, citalopram has also been shown to inhibit weakly noradrenalin reuptake, ${ }^{20,21}$ has some affinity for $\alpha_{1}$ adrenoreceptors and can act as a mild antihistaminic. ${ }^{22}$ Moreover, citalopram has very weak affinity for muscarinic cholinergic receptors. ${ }^{20,} 21$ The therapeutic dose range of citalopram is between 10 and $60 \mathrm{mg} /$ day. To avoid effects via nonserotoninergic mechanisms we chose to dose $20 \mathrm{mg}$, and we assume that the observed effects of citalopram at this dose are mediated via enhanced release serotonin, which activates 5-HT receptors.

During the infusion, citalopram decreased basal gastric tone. This finding indicates that 5-HT release is involved in the balancing of inhibitory and excitatory stimuli that regulate basal gastric muscle tone. Indeed, in-between meals, the proximal stomach muscle tone is elevated, partly due to the myoelectrical properties of the fundus, ${ }^{23}$ besides a constant cholinergic input mediated by the vagal nerves. ${ }^{24}$ Although contractile factors are dominant, there is also an inhibitory component active in the regulation of gastric tone: inhibition of nitric oxide synthase has been shown to decrease basal gastric tone. ${ }^{25}$ Our present findings indicate that also 5- $\mathrm{HT}$ release is part of this balance. Possible receptors that could decrease gastric tone are $5-\mathrm{HT}_{1}, 5-\mathrm{HT}_{4}$ and $5-\mathrm{HT}_{7}$ receptors. ${ }^{4}{ }^{26-28}$ It has been shown that the $5-\mathrm{HT}_{4}$ receptor
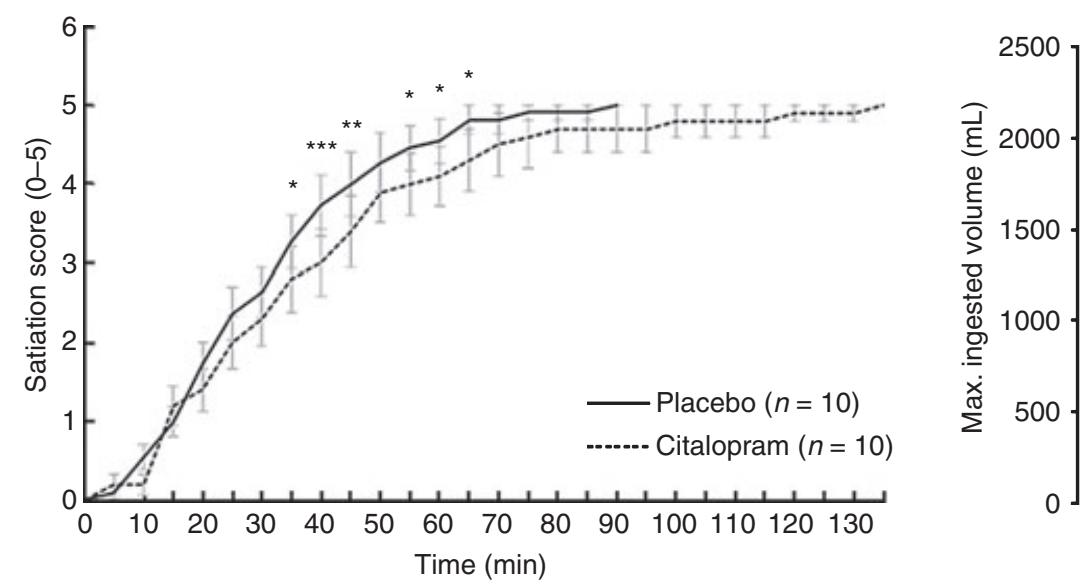

Figure 3 | Satiation score over time during the drink test after treatment with citalopram was significantly lower compared to placebo (left panel; $P=0.01$ ). Statistical differences at individual time points are indicated as follows: ${ }^{\star} P<0.05,{ }^{\star \star} P<0.01,{ }^{\star \star \star} P<0.001$. Volunteers drank significantly more after citalopram treatment (right panel; $P<0.05)$. 


\section{P. Janssen et al.}

antagonist R216073 did not affect basal gastric volumes, ${ }^{10}$ which indicates that $5-\mathrm{HT}_{1}$ and/or $5-\mathrm{HT}_{7}$ receptors could be more likely candidates.

Upon food intake, the physiology of the stomach changes dramatically. A vago-vagal reflex pathway is activated that inhibits cholinergic contractile input and increases the release of nitric oxide, especially to the proximal stomach. $^{29}$ This reflex, also referred to as gastric accommodation, enhances the storage capacity of the stomach. In this study, citalopram decreases gastric accommodation to the meal, indicating that during that gastric accommodation endogenous 5-HT release activates 5 -HT receptors that inhibit the accommodation reflex. Although we found no study that could mimic this effect using a 5-HT receptor agonist in humans or other species, in vitro studies in the dog indicate that activation of $5-\mathrm{HT}_{2}$ receptors might be responsible for the observed effect. ${ }^{30}$ Our results are seemingly in contrast with our previous finding that long-term treatment with paroxetine enhanced mealinduced gastric accommodation. ${ }^{11}$ However, long-term enhanced release of 5-HT might lead to receptor desensitisation, ${ }^{16}$ which might indeed lead to opposite effects as compared to short-term treatment and might explain the observed differences. ${ }^{14,15}$ This observation does suggest that the effects observed with 7 days' paroxetine pre-treatment reflect receptor desensitisation rather than enhanced availability of synaptically released 5 -HT. ${ }^{11}$

The present study furthermore indicates that citalopram accelerates gastric emptying of solids but not of liquids. This finding is seemingly in contrast with a previous finding that could not find any differences in gastric emptying after chronic treatment with paroxetine or venlafaxine-XR. ${ }^{12}$ Once again, the difference might be attributed by the treatment duration, but the noradrenaline reuptake inhibitory effects of venlafaxine may also account for this difference, as adrenergic receptor activation decreases gastric contractility and gastric empty-

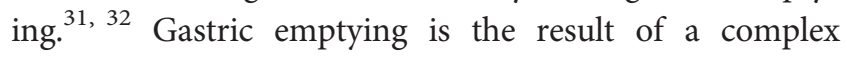
interplay between the major motor patterns of the stomach. Tonic contractions of the proximal stomach propel gastric content distally, whereas peristaltic contractions emerging from the mid-corpus progress in the direction of the antrum. A third mechanical factor in the regulation of GE is opening and closure of the pylorus. The relative importance of each of these three mechanical functions depends on food consistency: for liquids the pressure elicited by the proximal stomach and opening of the pylorus will drive gastric emptying, whereas the peristaltic pump of the antrum is crucial for grinding and emptying of solid food. ${ }^{33} 5-\mathrm{HT}_{4}$ receptor agonists like tegaserod ${ }^{34}$ and cisapride ${ }^{35}$ have been shown to accelerate gastric emptying of solids and also in the present study the enhanced availability of 5-HT could activate $5-\mathrm{HT}_{4}$ receptors. Despite the effect on solid gastric emptying and the marked effect on gastric accommodation, acute treatment with citalopram did not significantly enhance gastric emptying of liquids. Very few agents, with the exception of motilin receptor agonists such as erythromycin, ${ }^{36}$ are able to enhance liquid gastric emptying in health. It is conceivable that more significant effects could be observed in patients with delayed (liquid) gastric emptying.

Citalopram has been suggested for the treatment of obesity and binge eating disorder. ${ }^{37,} 38$ In the latter studies, however, the proposed mechanism of action implicated the antidepressive properties of citalopram, rather than a direct effect on food intake. In our study, acute treatment with citalopram was associated with lower satiation scores during the drinking test and increased the volume of nutrient drink ingested before volunteers scored maximal satiation. We previously showed that treatments that decreased gastric accommodation to a meal also enhanced meal-induced satiation. ${ }^{29,39,40}$ On the other hand, drugs like sumatriptan, buspirone and cisapride that increased meal-induced gastric accommodation also enhance food intake to maximum satiety. 3 , 39 As citalopram decreased gastric accommodation to a meal, we expected a decreased nutrient tolerance. It is therefore likely that other effects mediated by 5-HT might be responsible for the observed effect on food intake. Central 5-HT is well known to play a complex role in the regulation of satiation and satiety and influences neurons in the arcuate nucleus, the ventromedial nucleus and other parts of the hypothalamus. ${ }^{41-43}$ Enhanced availability of 5-HT at the central level might provide an explanation for our findings. Although the observed effect in the present study was significant, it was not observed in all volunteers, and future studies will have to address whether this acute effect might play a role in the anorectic effect of long-term citalopram treatment that is suggested to be mediated via 5-HT receptor desensitisation. ${ }^{37,38}$

In conclusion, acute treatment with the selective 5-HT reuptake inhibitor citalopram decreases basal gastric tone, impairs gastric accommodation to a meal, enhances gastric emptying of solids and increases the volume of nutrient drink ingested before volunteers scored maximal satiation. The observed effects are probably mediated via 
enhanced availability of 5-HT and indirectly indicate an important role for 5-HT in the control of gastric motility and food intake. This study warrants further short- and long-term studies with selective 5-HT receptor agonists and antagonists to elucidate further the underlying mechanisms and clinical implications.

\section{ACKNOWLEDGEMENTS}

Declaration of personal interests: Pieter Janssen and Lukas Van Oudenhove are postdoctoral research fellows of the FWO Flanders. Declaration of funding interests: This work was supported by an FWO grant and a Methusalem grant to Jan Tack, MD, PhD.

\section{REFERENCES}

1. Gershon MD, Tack J. The serotonin signaling system: from basic understanding to drug development for functional GI disorders. Gastroenterology 2007; 132: 397-414.

2. Neal KB, Parry LJ, Bornstein JC. Strainspecific genetics, anatomy and function of enteric neural serotonergic pathways in inbred mice. J Physiol 2009; 587: 386.

3. Van Oudenhove L, Kindt S, Vos R, Coulie B, Tack J. Influence of buspirone on gastric sensorimotor function in man. Aliment Pharmacol Ther 2008; 28: 132633.

4. Tack J, Coulie B, Wilmer A, Andrioli A, Janssens J. Influence of sumatriptan on gastric fundus tone and on the perception of gastric distension in man. Gut 2000; 46: 468-73.

5. Coleman NS, Marciani L, Blackshaw E, et al. Effect of a novel 5-HT3 receptor agonsit MKC-733 on upper gastrointestinal motility in humans. Aliment Pharmacol Ther 2003; 18: 1039-48.

6. Klatt S, Bock W, Rentschler J, Beckh K, Adler G. Effects of tropisetron, a 5-HT3 receptor antagonist, on proximal gastric motor and sensory function in nonulcer dyspepsia. Digestion 1999; 60: 147-52.

7. Marzio L, Cappello G, Grossi L, Manzoli L. Effect of the 5-HT3 receptor antagonist, ondansetron, on gastric size in dyspeptic patients with impaired gastric accommodation. Digest Liver Dis 2008; 40: $188-93$.

8. Netzer P, Gaia C, Lourens ST, et al. Does intravenous ondansetron affect gastric emptying of a solid meal, gastric electrical activity or blood hormone levels in healthy volunteers? Aliment Pharmacol Ther 2002; 16: 119-27.

9. Kuo B, Camilleri M, Burton D, et al. Effects of 5-HT(3) antagonism on postprandial gastric volume and symptoms in humans. Aliment Pharmacol Ther 2002; 16: 225-33.

10. Van Lelyveld N, Ter Linde J, Baron A, Mundt M, Wajs E, Samsom M. The 5HT4 antagonist R216073 does not affect gastric motor and sensory function in patients with functional dyspepsia. Aliment Pharmacol Ther 2006; 24: 669-77.

11. Tack J, Broeckaert D, Coulie B, Fischler $B$, Janssens J. Influence of the selective serotonin re-uptake inhibitor, paroxetine, on gastric sensorimotor function in humans. Aliment Pharmacol Ther 2003; 17: 603-8.

12. Chial HJ, Camilleri M, Burton D, Thomforde G, Olden KW, Stephens D. Selective effects of serotonergic psychoactive agents on gastrointestinal functions in health. Am J Physiol Gastrointest Liver Physiol 2003; 284: G130-7.

13. Ladabaum U, Glidden D. Effect of the selective serotonin reuptake inhibitor sertraline on gastric sensitivity and compliance in healthy humans. Neurogastroenterol Motil 2002; 14: 395-402.

14. Bonhomme N, Esposito E. Involvement of serotonin and dopamine in the mechanism of action of novel antidepressant drugs: a review. J Clin Psychopharmacol 1998; 18: 447-54.

15. Hetrick S, Merry S, McKenzie J, Sindahl $\mathrm{P}$, Proctor M. Selective serotonin reuptake inhibitors (SSRIs) for depressive disorders in children and adolescents. Cochrane Database Syst Rev 2007; 3: CD004851.

16. Cremers TI, Spoelstra EN, de BP, et al. Desensitisation of 5-HT autoreceptors upon pharmacokinetically monitored chronic treatment with citalopram. Eur J Pharmacol 2000; 397: 351-7.

17. Maes BD, Ghoos YF, Geypens BJ, et al. Combined carbon-13-glycine/carbon-14octanoic acid breath test to monitor gastric emptying rates of liquids and solids. J Nucl Med 1994; 35: 824-31.

18. Sarnelli G, Caenepeel P, Geypens B, Janssens J, Tack J. Symptoms associated with impaired gastric emptying of solids and liquids in functional dyspepsia. Am J Gastroenterol 2003; 98: 783-8.

19. Kindt S, Coulie B, Wajs E, Janssens J, Tack J. Reproducibility and symptomatic predictors of a slow nutrient drinking test in health and in functional dyspepsia. Neurogastroenterol Motil 2008; 20: $320-9$.
20. Pawlowski L, Nowak G, Gorka Z, Mazela H. Ro 11-2465 (cyan-imipramine), citalopram and their N-desmethyl metabolites: effects on the uptake of 5hydroxytryptamine and noradrenaline in vivo and related pharmacological activities. Psychopharmacology 1985; 86: 15663.

21. Milne RJ, Goa KL. Citalopram. A review of its pharmacodynamic and pharmacokinetic properties, and therapeutic potential in depressive illness. Drugs 1991; 41: 450-77.

22. Owens MJ, Morgan WN, Plott SJ, Nemeroff CB. Neurotransmitter receptor and transporter binding profile of antidepressants and their metabolites. J Pharmacol Exp Ther 1997; 283: 1305-22.

23. el Sharkawy TY, Morgan KG, Szurszewski JH. Intracellular electrical activity of canine and human gastric smooth muscle. J Physiol 1978; 279: 291-307.

24. Azpiroz F, Malagelada JR. Importance of vagal input in maintaining gastric tone in the dog. J Physiol 1987; 384: 511-24.

25. Paterson CA, Anvari M, Tougas G, Huizinga JD. Nitrergic and cholinergic vagal pathways involved in the regulation of canine proximal gastric tone: an in vivo study. Neurogastroenterol Motil 2000; 12: 301-6.

26. Janssen P, Prins NH, Moreaux B, Meulemans AL, Lefebvre RA. Characterization of 5 - $\mathrm{HT}_{7}$-receptor-mediated gastric relaxation in conscious dogs. Am J Physiol Gastrointest Liver Physiol 2005; 289: G108-15.

27. Janssen P, Prins NH, Moreaux B, Meulemans AL, Lefebvre RA. In vivo characterization of 5-HT1A receptor-mediated gastric relaxation in conscious dogs. $\mathrm{Br} \mathrm{J}$ Pharmacol 2003; 140: 913-20.

28. Thumshirn M, Fruehauf H, Stutz B, Tougas G, Salter J, Fried M. Clinical trial: effects of tegaserod on gastric motor and sensory function in patients with functional dyspepsia. Aliment Pharmacol Ther 2007; 26: 1399-407.

29. Tack J, Demedts I. Role of nitric oxide in the gastric accommodation reflex and in meal induced satiety in humans. Gut 2002; 51: 219-24. 


\section{P. Janssen et al.}

30. Janssen P, Prins NH, Meulemans AL, Lefebvre RA. Pharmacological characterization of the 5-HT receptors mediating contraction and relaxation of canine isolated proximal stomach smooth muscle. Br J Pharmacol 2002; 136: 321-9.

31. Gremlich HU, Martinez V, Kneuer R, et al. Noninvasive assessment of gastric emptying by near-infrared fluorescence reflectance imaging in mice: pharmacological validation with tegaserod, cisapride, and clonidine. Mol Imaging 2004; 3: 303-11.

32. Martinez V, Cuttitta F, Tache Y. Central action of adrenomedullin to inhibit gastric emptying in rats. Endocrinology 1997; 138: 3749-55.

33. Indireshkumar K, Brasseur JG, Faas H, et al. Relative contributions of "pressure pump" and "peristaltic pump" to gastric emptying. Am J Physiol Gastrointest Liver Physiol 2000; 278: 604-16.

34. Degen L, Matzinger D, Merz M, et al. Tegaserod, a 5-HT4 receptor partial ago- nist, accelerates gastric emptying and gastrointestinal transit in healthy male subjects. Aliment Pharmacol Ther 2001; 15: 1745-51.

35. Cremonini F, gado-Aros S, Talley NJ. Functional dyspepsia: drugs for new (and old) therapeutic targets. Best Pract Res Clin Gastroenterol 2004; 18: 717-33.

36. Arts J, Caenepeel P, Verbeke K, Tack J. Influence of erythromycin on gastric emptying and meal related symptoms in functional dyspepsia with delayed gastric emptying. Gut 2005; 54: 455-60.

37. Appolinario JC, Bueno JR, Coutinho W. Psychotropic drugs in the treatment of obesity: what promise? CNS Drugs 2004; 18: 629-51.

38. McElroy SL, Hudson JI, Malhotra S, Welge JA, Nelson EB, Keck PE Jr. Citalopram in the treatment of binge-eating disorder: a placebo-controlled trial. $J$ Clin Psychiatry 2003; 64: 807-13.

39. Tack J, Caenepeel P, Piessevaux H, Cuomo R, Janssens J. Assessment of meal induced gastric accommodation by a satiety drinking test in health and in severe functional dyspepsia. Gut 2003; 52: 1271-7.

40. Geeraerts B, Mimidis K, Van Oudenhove L, Vos R, karamanolis G, Tack J. Role of endogenous opioids in the control of gastric sensorimotor function. Neurogastroenterol Motil 2008; 20: 1094-102.

41. Halford JC, Harrold JA, Lawton CL, Blundell JE. Serotonin (5-HT) drugs: effects on appetite expression and use for the treatment of obesity. Curr Drug Targets 2005; 6: 201-13.

42. Leibowitz SF, Alexander JT. Hypothalamic serotonin in control of eating behavior, meal size, and body weight. Biol Psychiatry 1998; 44: 851-64.

43. Fetissov SO, Meguid MM. Serotonin delivery into the ventromedial nucleus of the hypothalamus affects differently feeding pattern and body weight in obese and lean Zucker rats. Appetite 2010; 54: 346-53. 